\title{
Editorials
}

\section{The technological paradox of health inequality, and a probe with a practical tool}

Many have learned from Professor Jeremy Morris, either directly or from his publications. Many others across the world have sometimes unknowingly followed his path. In July this year all had cause to celebrate his 90th birthday and honour him as an inspiration and founder of a broad gauged modern epidemiology. In this issue of the journal, ${ }^{1}$ writing with colleagues, he demonstrates his characteristic lifelong ingenuity and directness in the study of important public health problems. Not least among these is the search for keys to health across all sections of society. For many years and over the past 20 years especially, he has sharpened our insight into the iniquities of inequity. This new paper looks to answer a practical question posed by the emergent understanding of inequalities. More of this below.

Meanwhile, I turn to the context that gives the new paper broader meaning. Among the many accompaniments of social inequality, we can say with confidence that material differences and resources are an important element in creating health disparities. The Black Report of 1980, coauthored by Jerry Morris with Douglas Black, Cyril Smith, and Peter Townsend, ${ }^{2}$ stimulated much research devoted to demonstrating and explaining such disparities. This was so especially but not only in Britain, with little of the work welcomed by authorities faced with the ensuing political problem.

The link between poverty and disease has long been known. Johann Peter Frank in late 18th century Germany called poverty "the mother of disease". Quantitative epidemiological study begins some decades later with Villermé. In 1826, he demonstrated across Parisian districts a gradient in mortality in close accord with the percentage of rents too low to tax; in 1840, in a six year study of the textile town of Mulhouse, he found striking gradients by occupation.

What is remarkable thereafter regarding social health gradients is that, in countries yielding requisite data, nowhere do they disappear. ${ }^{4}$ Thus a first paradox is that gradients however measured persist despite huge changes in disease patterns and accompanying declines within all classes in mortality and morbidity, and despite equally large increases in wealth, resources, knowledge and technology. Nor has substantial social mobility, with redistribution of occupations and class size, been shown to create a postulated artefact of an unchanging class distribution of health and disease. ${ }^{5}$

A second paradox, more immediate and even less anticipated, became known to us only in the late 20th century. In England and Wales, this resides in a gap between rich and poor for relative measures of mortality (and morbidity where available) that is not only sustained but widening over the past 50 years or more. In subsequent observation, the same phenomenon appears elsewhere as well. Such a trend, found across those developed countries subjected to appropriate analysis, defies the cumulation of resources and alleviation of the worst aspects of material poverty and ill health. To take a few examples among many, a widening gap for mortality against measures of income and education is seen in the United States between 1960 and
$1986,{ }^{6}$ and for mortality against occupation (non-manual versus manual) across 11 European countries between 1970 and $1980 .^{7}$ For England and Wales, systematic national mortality analyses from 1911 onwards supply the largest and longest set of such existing data. These recur periodically around every decennial census (excepting the non-census phase around 1941 during the second world war). Although we have learned that differences in health from the best off to the worst off are finely graded, ${ }^{8}$ the unignorable general trend reflects both improving mortality and a widening gap between classes. Observed departures from the trend are brief and small.

Two substantial recent analyses of these and other British data, by indefatigable researchers following up on the Black Report, leave no doubt of the existence of this paradox of widened relative social disparity in face of improving health indices. An official volume, Health Inequalities edited by Drever and Whitehead, ${ }^{9}$ begins with a review of changes over the millennium, and carries through to the most recently published British census of 1991. A second volume, The Widening Gap, by Shaw and colleagues, ${ }^{10}$ draws on data both from the British Office of National Statistics and from a special sample - a million each drawn from the best off and the worst off constituencies in the country.

This takes us to the question of what could account for such paradoxical trends. The finding of Wilkinson ${ }^{11}$ - for an array of countries with the necessary data-that the greater the levels of income inequality the higher the standardised mortality rates was followed by other findings of similar correlations among smaller units such as states and counties. To explain this relation, he has since proposed such sociopsychological mechanisms as "hierarchical stress" (alias relative deprivation). Davey Smith and others have countered vigorously; their explanations, supported by the extensive data of Shaw et al, ${ }^{10}$ are rooted in material deprivation. Link and Phelan ${ }^{12}$ offer the broad idea of "fundamental social causes" as the sum of adverse social conditions. One might see these as a continuum, through the lifecourse, of strata of relative disadvantage with bearing on all the material and social resources that affect health.

A third paradox is the persistence of the social health gap in the face of changes in both the nature of disease and of its causes, and thus its seeming independence from them. This independence must be dealt with if one is to explain the growing gap. The relation between health risks and social position is dynamic; it evolves through time and life course, which is to say the history of society and individuals interacting. My interpretation of this paradox follows from the view that in any society at any time, not only are health, disease and death shaped by societal factors ${ }^{4}$ but that this occurs in a singular manner. The singularity in such dynamic shaping is that in modern times it continuously and increasingly favours those already socially favoured. However, risks might change, graded social advantage confers growing advantage in the power, prestige and resources to extract parallel advantage in the 
education, knowledge, income and environment essential to sustaining health.

One might describe this evolving modern dynamic as "technological backlash". Its essence lies in two processes: on the one hand, accelerated discovery and technical efficacy in maintaining health and preventing and treating its disorder; on the other hand, concurrent maldistribution of technical and overall advantage in society at large. Although greater efficacy in sustaining health eventually improves health for all, it does so first and most for the more socially favoured. Hence the greater the overall absolute improvement, the greater the effect on the relative distance between the most and least favoured.

Some recent studies across several European countries and the United States find rising inequalities of morbidity and/or mortality (measured variously) in relation to social position (also measured variously). ${ }^{613-15}$ At first sight, these present something of a conundrum. But the results are in fact compatible with the idea of technological backlash.

As hypothesised, where morbidity and mortality in absolute terms are generally low, see most Scandinavian countries, in relative terms inequalities across social positions are generally greater than elsewhere. Also consistent is the fact that, since comparative health indices became available in the second half of the 20th century, Scandinavians have led the overall improvements in European health. Thus the pattern seems to hold.

The same process has more limited expression, I would argue, in the downward mobility from upper to lower classes of modern scourges that proved amenable to prevention by controlling risk factors such as smoking. ${ }^{4}$ Smoking itself, coronary heart disease and lung cancer all demonstrate this pattern.

Bleak as the outlook for a move toward equality may appear in this light, we need not despair. The forces mobilised by public health have made and can make differences at a societal level by deliberate measures to tackle specific health problems and the propulsion of social health movements. Thus Shaw et $a l^{10}$ have made incontrovertibly clear once more that material resources matter to health. To increasing material resources, one can add the incontrovertible role of public health movements and education in many domains such as sanitation, smoking and other behaviour in improved health.

Here I return to the paper of Morris et al. ${ }^{1}$ In the spirit of good research and in the hope of stimulating debate, the authors put a direct and relevant question. Their focus is the pressing and limited problem of the resources needed to sustain health, at the bottom end of the scale and in its simplest dimensions. Thus the study asks what today is the precise cash expenditure needed by a single man aged 18 to 30 years in the UK to meet reasonable requirements for a healthy life in the light of current knowledge.

Costs were derived from ad hoc surveys, available national data and, for a few minor items, by estimates. Naturally they must make some assumptions in arriving at their answers. They find, disturbingly, that minimum costs are greater than the minimum wage level for those employed and well above basic social security for those not employed. This straightforward but original paper can well be seen as a forerunner that places an obligation on others to examine the material needs of defined groups, for instance, the aged, women with young families, and others not at the lower margin of poverty too. It shows one route towards measuring and meeting identified social disadvantage adverse to health.

MERVYN SUSSER

Columbia University, Sergievsky Center, 530 W 168th Street,

PES Box 16, New York, NY 10032, USA

1 Morris JM, Donkin AK, Wonderling D, et al. A minimum income for healthy living. F Epidemiol Community Health 2000;54:885-9.

2 Townsend P, Davidson N, eds. Inequalities in health: the Black Report. Harmondsworth: Penguin Books, 1982.

3 Rosen G. A history of public health. Expanded edition. Baltimore: Johns Hopkins University Press, 1993.

4 Susser M, Watson W, Hopper K. Sociology in medicine. New York: Oxford University Press, 1985.

5 Fox AJ, Goldblatt PO, Jones DR. Social class mortality differentials: artefact, selection or life circumstances? $\mathcal{F}$ Epidemiol Community Health 1985;39:1-8.

6 Pappas G, Queen S, Hadden W, et al. The increasing disparity in mortality between socioeconomic groups in the United States, 1960-1986. N Eng $\mathcal{F}$ Med 1993;329:103-9.

7 Kunst AE, Groenhof F, Mackenbach JP and the EU Working Group on Socioeconomic Inequalities in Health. Occupational class and cause specific mortality in middle aged men in 11 European countries: comparispecific mortality in middle aged men in 11 European countr
son of population based studies. BMF 1998;316:1636-42.

8 Marmot MG, Davey Smith G, Stansfeld S, et al. Health inequalities among British civil servants: the Whitehall II study. Lancet 1991;337:1387-93.

9 Drever F, Whitehead M, eds. Health Inequalities. Decennial Supplement. Office of National Statistics. London: The Stationery Office, 1997.

10 Shaw M, Dorling D, Gordon D, et al. The widening gap: health inequalities and policy in Britain. Bristol: The Policy Press, University of Bristol, 1999.

11 Wilkinson RG. Income and mortality. In: Wilkinson RG, ed. Class and health: research and longitudinal data. London: Tavistock, 1986:88-114.

12 Link BG, Phelan J. Understanding sociodemographic differences in health: the role of fundamental causes. Am f Public Health 1996;86:471-3.

13 Mackenbach JP, Kunst AE, Cavelaars AE, et al. Socioeconomic inequalities in morbidity and mortality in Western Europe. The EU Working Group on in morbidity and mortality in Western Europe. The EU Working

14 Kunst AE, Groenhof F, Mackenbach JP. Mortality by occupational class among men 30-64 years in 11 European countries. EU Working Group on Socioeconomic Inequalities in Health. Soc Sci Med 1998;46:1459-76.

15 Sihvonen AP, Kunst AE, Lahelma E, et al. Socioeconomic inequalities in health expectancy in Finland and Norway in the late 1980s. Soc Sci Med 1998;47:303-15. 